\title{
Molecular Recognition Thermodynamics and Structural Elucidation of Interactions between Steroids and Bridged Bis( $\beta$-Cyclodextrin $) \mathrm{S}$
}

\author{
Yu Liu,* Ying-Wei Yang, En-Cui Yang, Xu-Dong Guan \\ Department of Chemistry, State Key Laboratory of Elemento-Organic Chemistry, \\ Nankai University, Tianjin 300071, P. R. China
}
*Corresponding author: Tel: +86-022-23503625; fax: +86-022-23503625; E-mail: yuliu@public.tpt.tj.cn

Figure S1 ROESY spectra of CA with a mixing time of $200 \mathrm{~ms}$ at 298K.

Figure S2 ROESY spectra of DCA with a mixing time of $200 \mathrm{~ms}$ at 298K.

Figure S3 ROESY spectrum of 5-CA with a mixing time of $300 \mathrm{~ms}$ at 298K.

Figure S4 ROESY spectrum of 5-DCA with a mixing time of $300 \mathrm{~ms}$ at 298K.

Figure S5 ROESY spectrum of 2-CA with a mixing time of $200 \mathrm{~ms}$ at 298K.

Figure S6 ROESY spectrum of 2-DCA with a mixing time of $200 \mathrm{~ms}$ at 298K.

Figure S7 ROESY spectrum of 2-GCA with a mixing time of $200 \mathrm{~ms}$ at 298K.

Figure S8 ROESY spectrum of 5-CA with a mixing time of $200 \mathrm{~ms}$ at 298K.

Figure S9 ROESY spectrum of 5-DCA with a mixing time of $200 \mathrm{~ms}$ at 298K.

Figure S10 ROESY spectrum of 7-CA with a mixing time of $200 \mathrm{~ms}$ at 298K.

Figure S11 ROESY spectrum of 7-DCA with a mixing time of $200 \mathrm{~ms}$ at 298K.
Page S2

Page S3

Page S4

Page S5

Page S6

Page S7

Page S8

Page S9

Page S10

Page S11

Page S12 

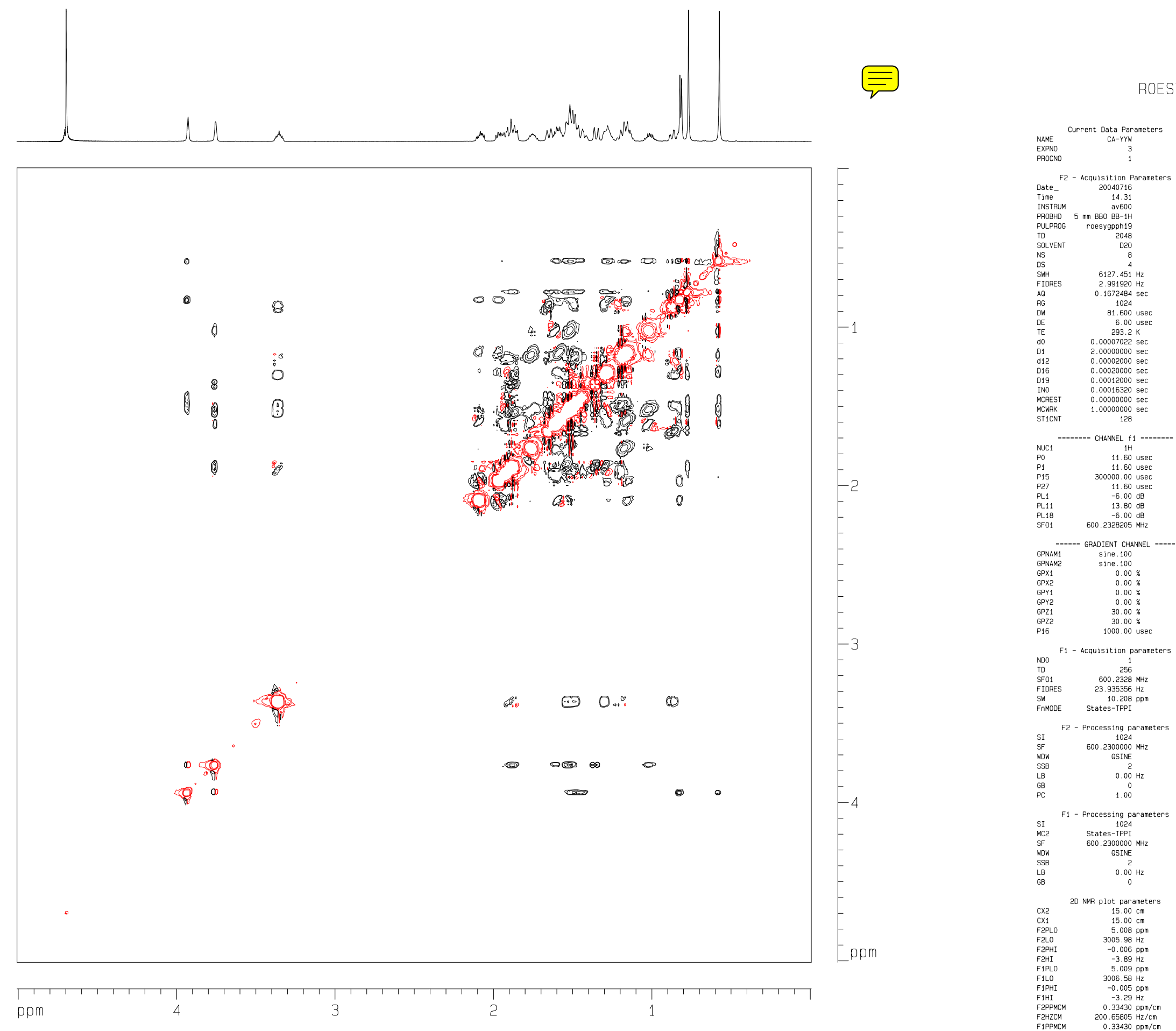
需

ROESYPH

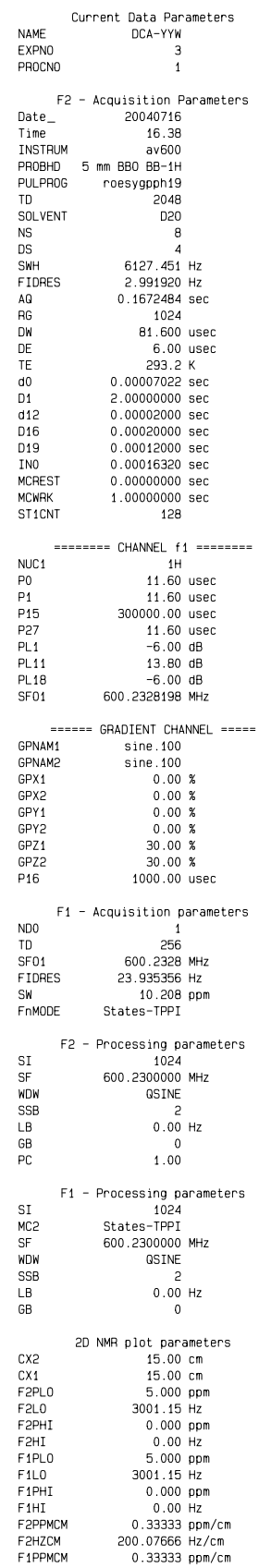



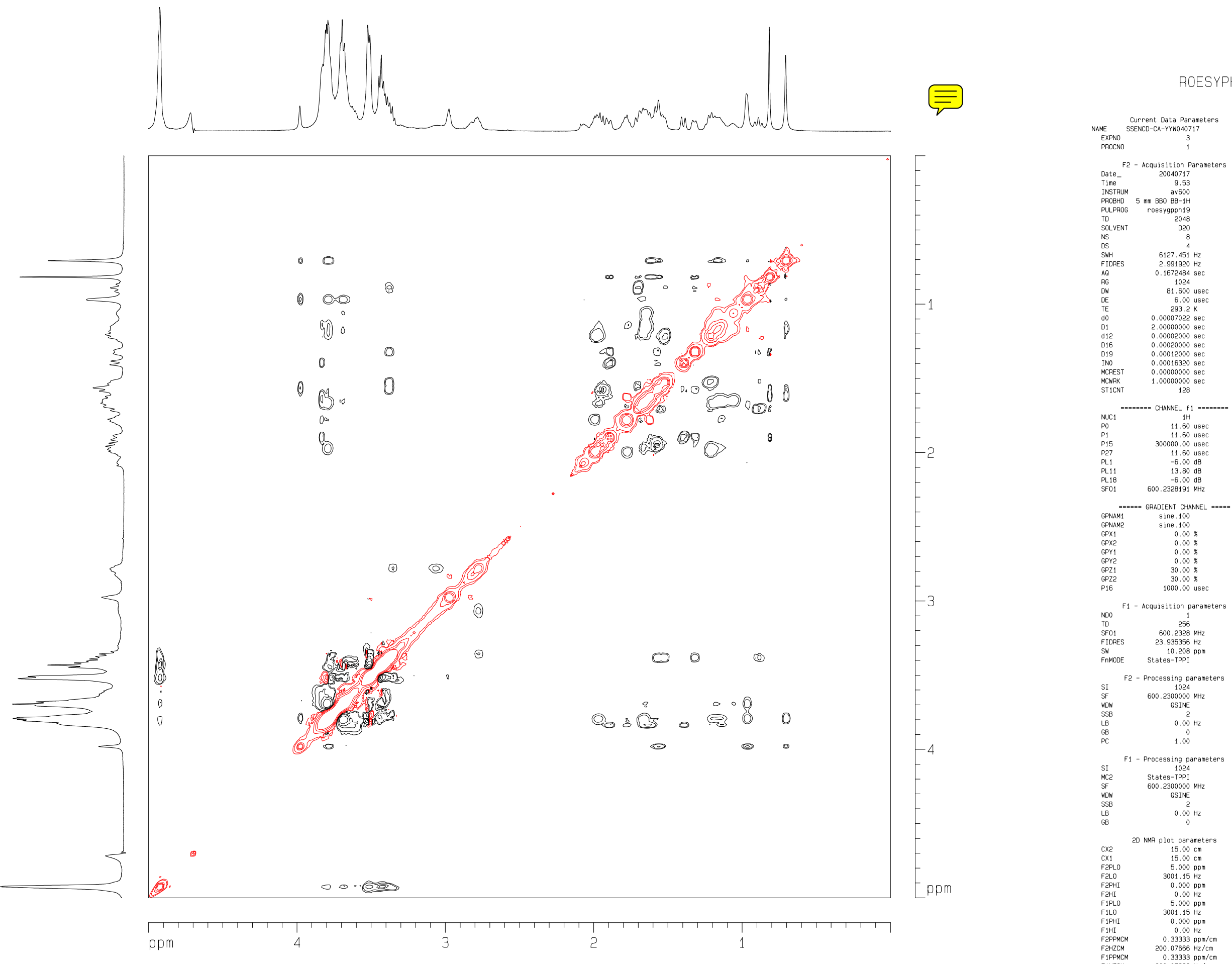
主

ROESYPH
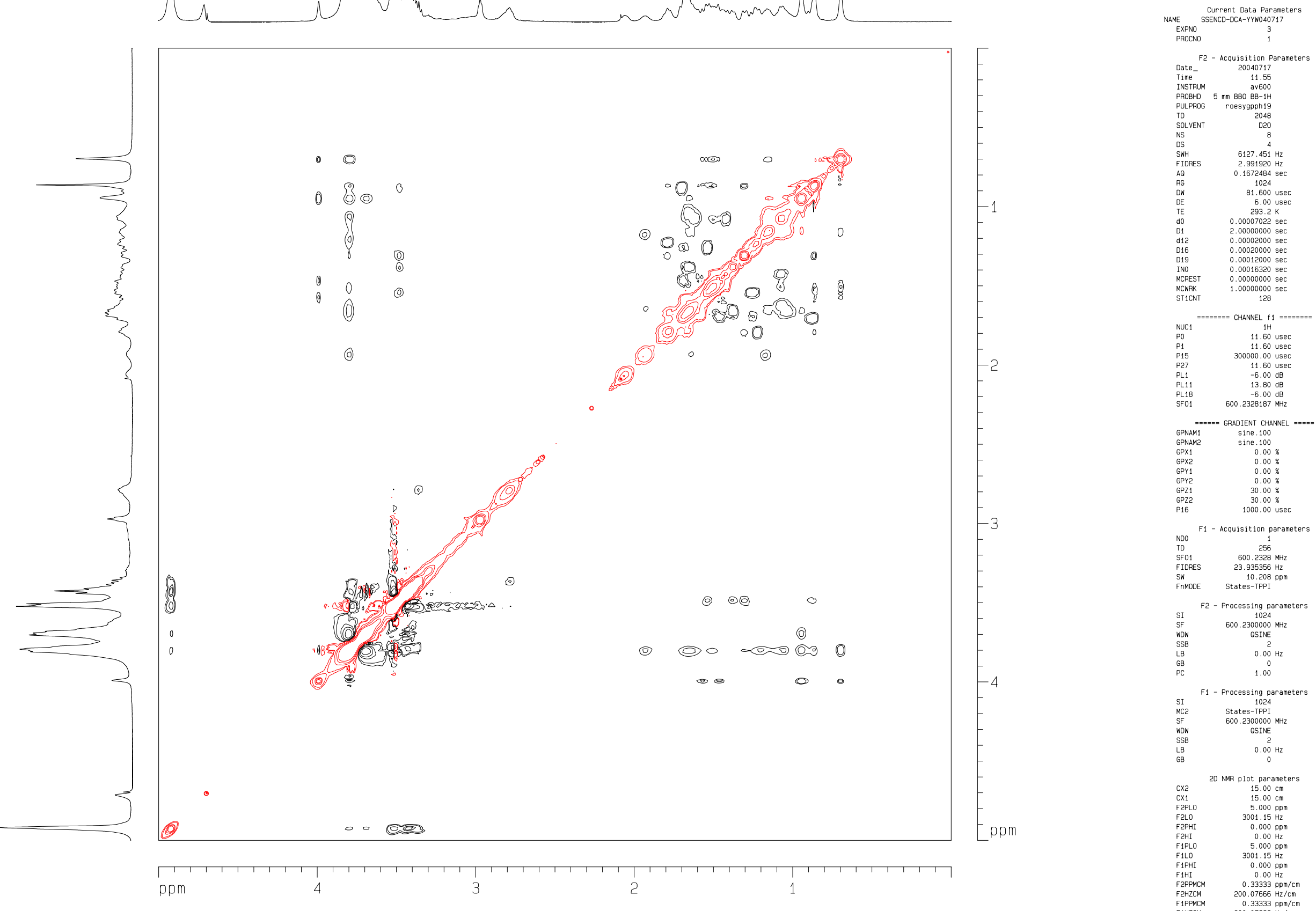


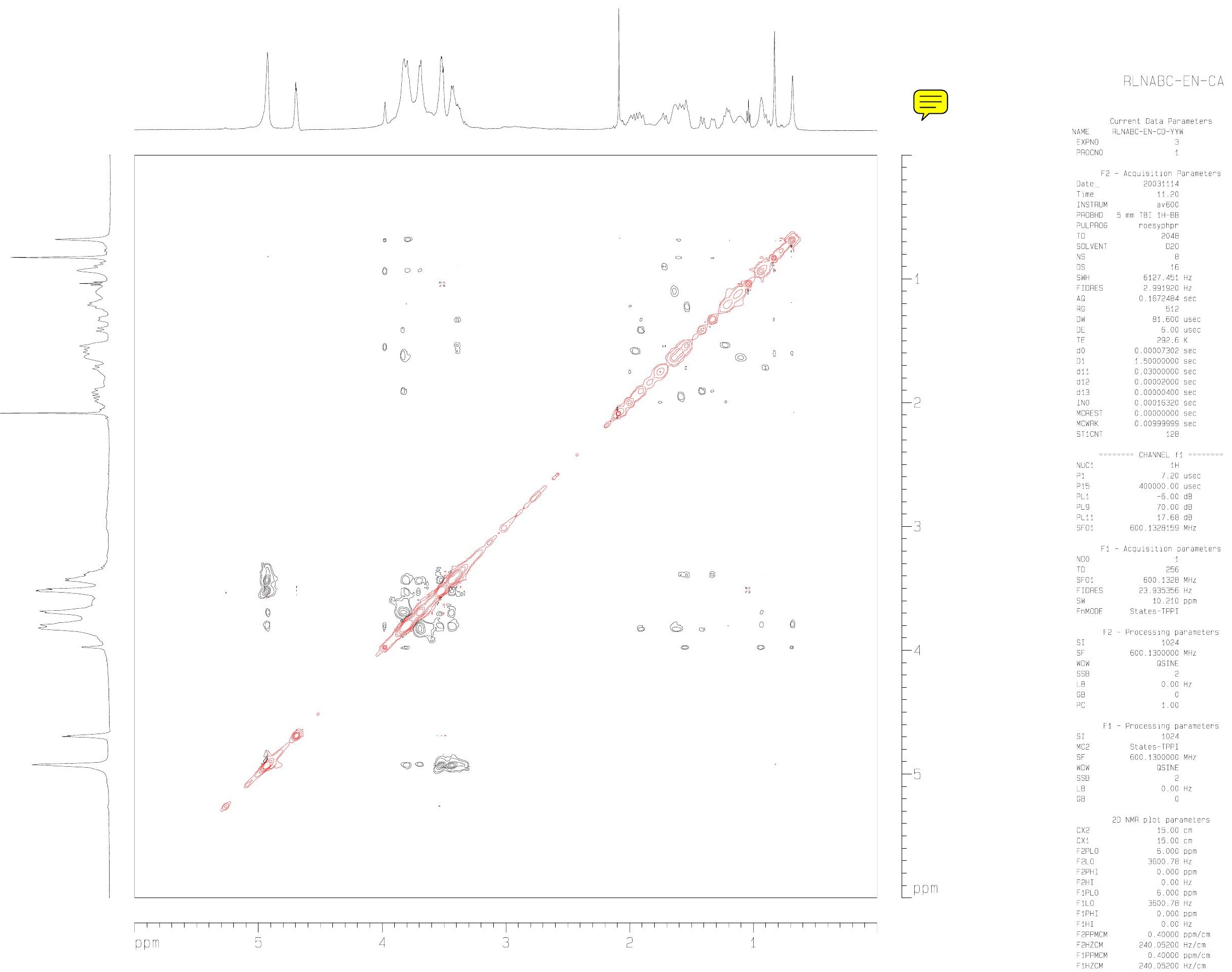




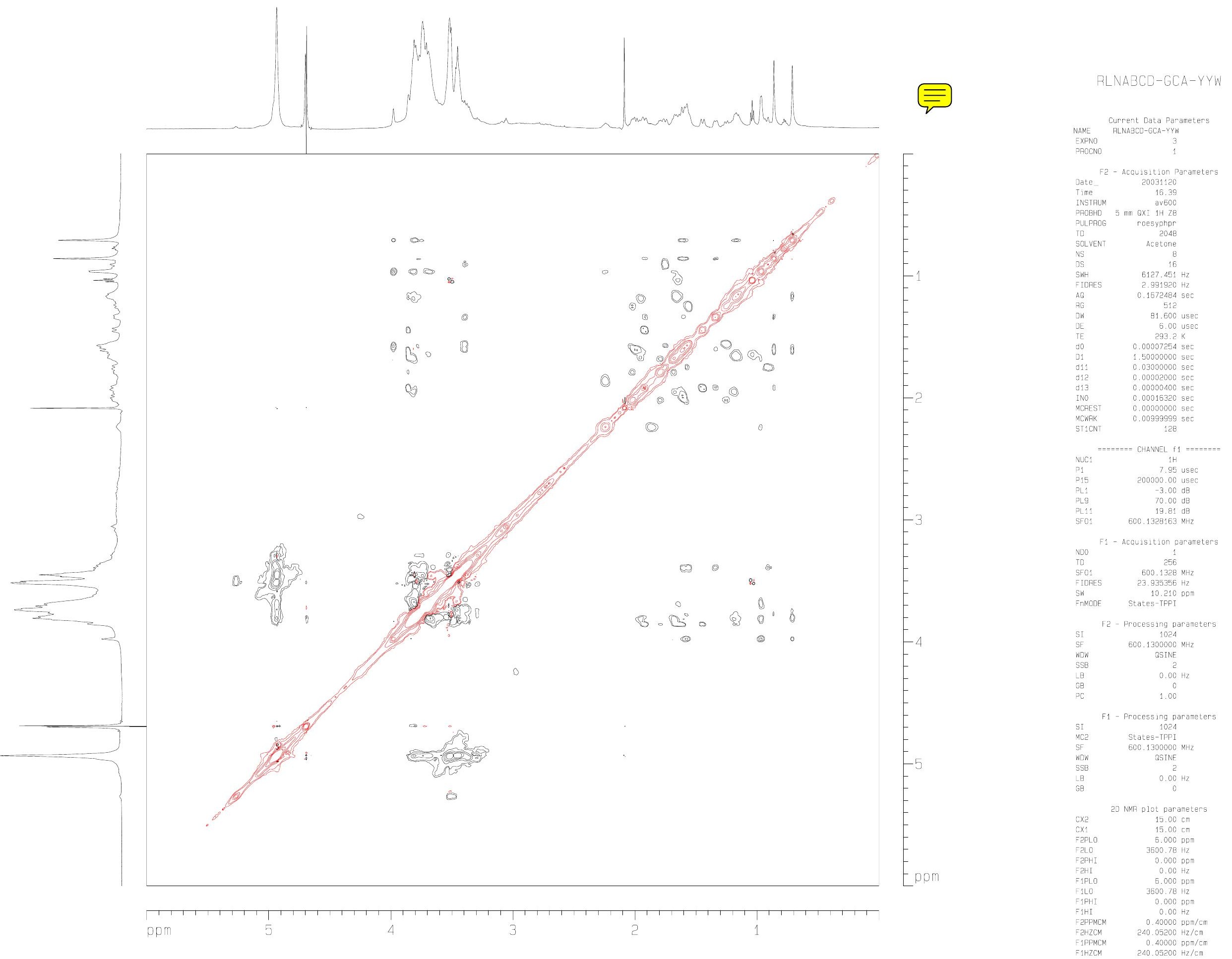




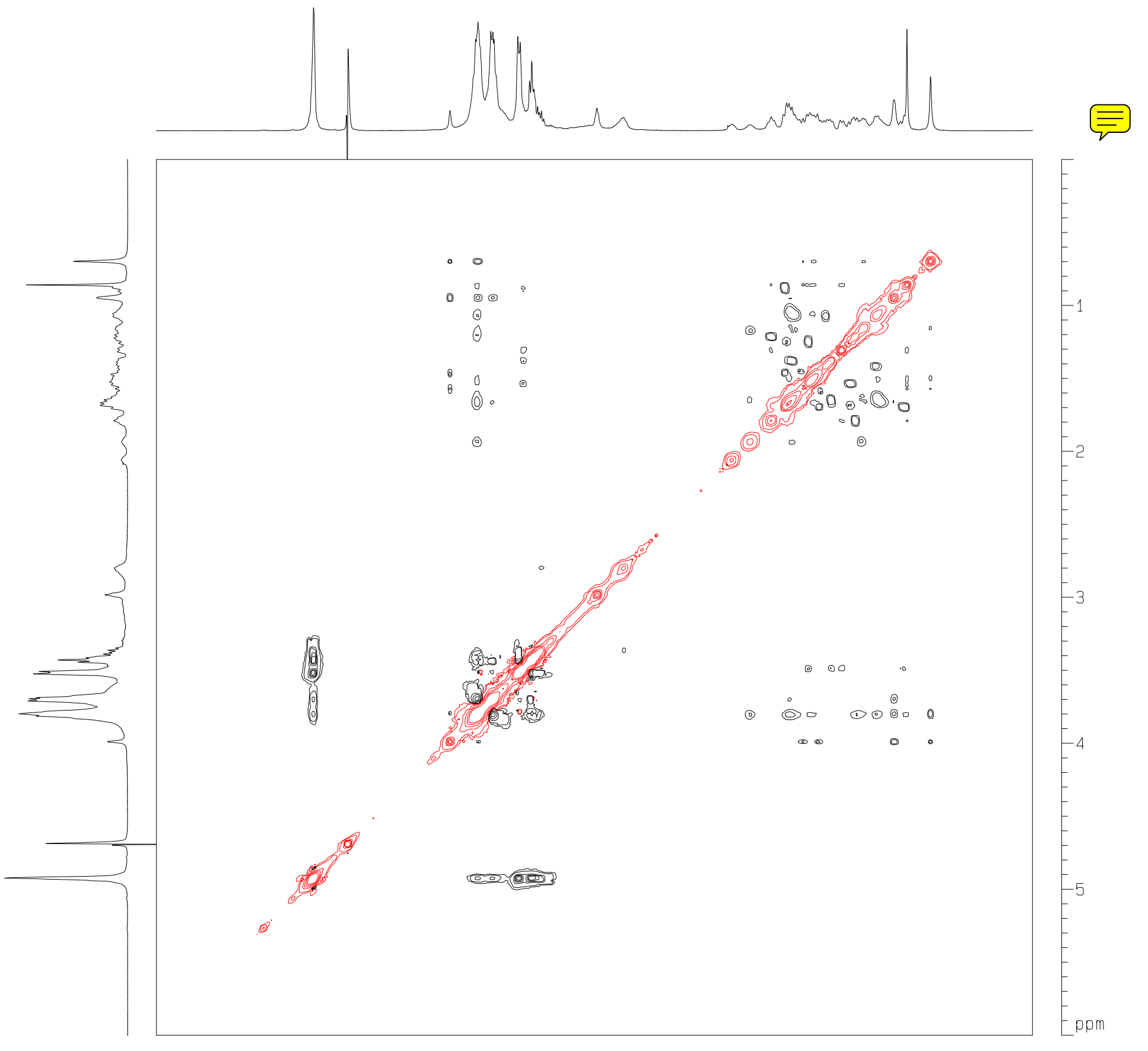

SSENBCD-DCA

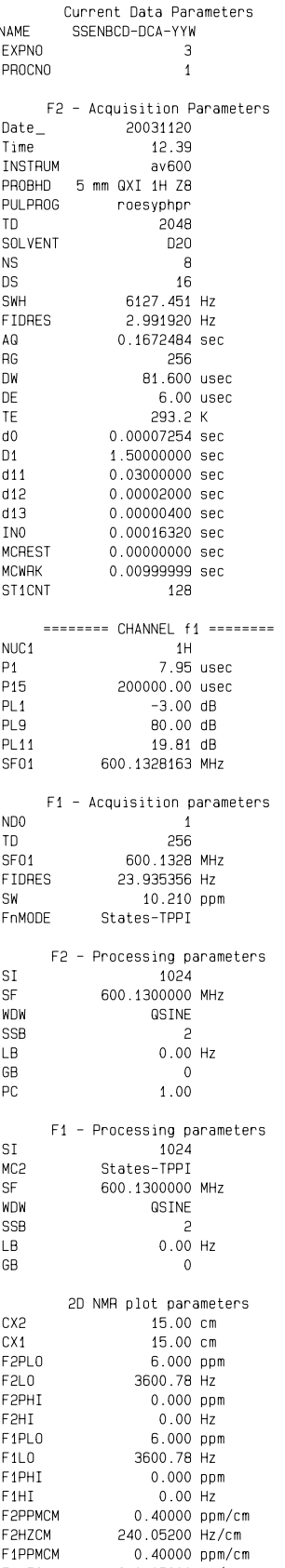




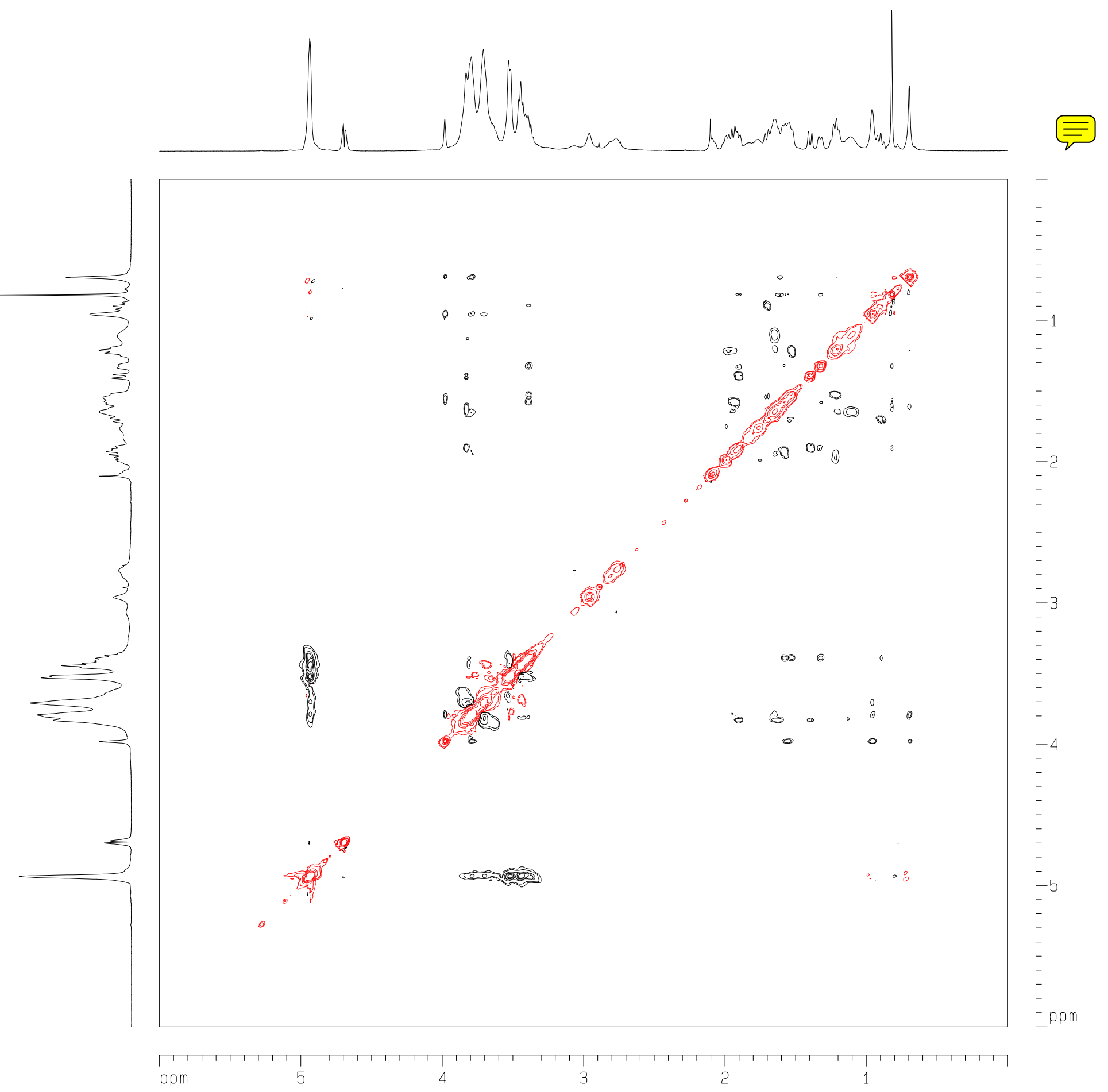


